\title{
Analysis of large new South African data set using two host specificity indices shows generalism in both adult and larval ticks of mammals
}

Marcela P. A. Espinaze ${ }^{1}$, Eléonore Hellard ${ }^{1}$, Ivan G. Horak ${ }^{2}$, Graeme S. Cumming ${ }^{1,3}$

Running title: Host specificity of South African ticks

${ }^{1}$ Percy FitzPatrick Institute, DST-NRF Centre of Excellence, University of Cape Town, Private Bag X3, Rondebosch 7701, South Africa.

${ }^{2}$ Department of Veterinary Tropical Diseases, Faculty of Veterinary Science, University of Pretoria, Private Bag X04, Onderstepoort, 0110 South Africa.

${ }^{3}$ ARC Centre of Excellence for Coral Reef Studies, James Cook University, Townsville, Queensland 4811, Australia.

Corresponding author: Marcela P. A. Espinaze. Percy FitzPatrick Institute, DST-NRF Centre of Excellence, University of Cape Town, Private Bag X3, Rondebosch 7701, South Africa. Phone: 0027-84-634-1612, fax: 0027-21-650-3295. Email: mares027@gmail.com.

\section{SUMMARY}

Ticks and tick-borne pathogens can have considerable impacts on the health of livestock, wildlife, and people. Knowledge of tick host preferences is necessary for both tick and pathogen control. Ticks were historically considered as specialist parasites, but the range of sampled host species has been limited, infestation intensity has not been included in prior 
analyses, and phylogenetic distances between hosts have not been previously considered. We used a large data set of 35,604 individual collections and two host specificity indices to assess the specificity of 61 South African tick species, as well as distinctions between adult and juvenile ticks, for 95 mammalian hosts. When accounting for host phylogeny, most adult and juvenile ticks behaved as generalists, with juveniles being significantly more generalist than adults. When we included the intensity of tick infestation, ticks exhibited a wider diversity of specificity in all life stages. Our results show that ticks of mammals in South Africa tend to behave largely as generalists and that adult ticks are more hostspecific. More generally, our analysis shows that the incorporation of life-stage differences, infestation intensity, and phylogenetic distances between hosts, as well as the use of more than one specificity index, can all contribute to a deeper understanding of host-parasite interactions.

Key words: Host-parasite interaction, ticks, host specificity, South Africa, Ixodidae.

\section{INTRODUCTION}

Ticks are obligate ectoparasites that feed on blood of a variety of host species, including birds, reptiles, amphibians and mammals (Klompen et al. 1996). They are vectors of many important pathogens, including protozoan, rickettsial, viral, bacterial and fungal organisms (Oliver, 1989; Sonenshine, 1991). Approximately 10\% of the 867 currently recognised tick species are known to transmit infectious microorganisms (Jongejan and Uilenberg, 2004) that threaten not only livestock and wildlife, but also human health, causing diseases such as heartwater, Lyme disease, and babesiosis (Karesh et al. 2005). Ticks may also cause severe damage to their hosts, including injuries to skin and hides, wounds, abscesses, and 
bleeding (Muchenje et al. 2008; Moyo and Masika, 2009); and they secrete substances that can generate toxicosis and host paralysis (Stone et al. 1989).

Tick host preferences are an important component of their ecology (Hoogstraal and Aeschlimann, 1982; Uilenberg, 1995; Cumming, 1998; Jongejan and Uilenberg, 2004). A parasite's host specificity is closely related to its ability to persist in a given environment and its potential to expand its range or colonise new areas (Poulin and Mouillot, 2003; Koh et al. 2004). A deep understanding of tick-host relationships is needed not only for comprehending the evolution and basic ecology of ticks, but also for the management and control of ticks and tick-borne pathogens, prediction of future changes in the epidemiology of tick-borne diseases, and proactive responses to relevant environmental drivers such as deforestation and climate change (Cumming and Van Vuuren, 2006).

Ticks were historically considered to be specialist parasites, exhibiting morphological adaptations to feed on particular hosts (Hoogstraal and Aeschlimann, 1982; Hoogstraal and Kim, 1985). For example, the soft tick Argas (Microargas) transversus feeds exclusively on the Galapagos giant tortoise (Geochelone elephantopus) (Hoogstraal et al. 1973). However, most ticks are able to feed on a greater variety of host species (Oliver, 1989; Cumming, 1998). Experimental studies have revealed that they can feed and reproduce successfully using a wide diversity of hosts (James and Oliver, 1990; Belan and Bull, 1995; Marques Lisbôa Lopes et al. 1998). In the wild, ticks are often collected from a limited number of species and may appear to be host specialists (Hoogstraal and Aeschlimann, 1982). Tick-host interactions are, however, influenced not only by the physiological and morphological characteristics of ticks and hosts (Sonenshine, 1993), but also by their habitat preferences (Klompen et al. 1996; Nava and Guglielmone, 2013). Ticks exhibiting preferences for certain micro- and macro-habitats, such as Ixodes species commonly found 
on bats (Chiroptera), may preferentially parasitize hosts living in similar habitats (Sonenshine, 1993; Klompen et al. 1996). Similarly, the nature of animal movements is such that ticks that are under-dispersed (clumped) in the environment will be more likely to be perceived as specialists, regardless of their true host preferences (Cumming, 2004).

For many tick-host combinations, there is still considerable uncertainty as to whether an absence of an observed tick-host interaction indicates that the interaction cannot occur or is simply a matter of it not having been observed (Klompen et al. 1996; Cumming, 1998, 2004; Petney et al. 2007). In addition, the most comprehensive previous analysis of tickhost specificity for African species (Cumming, 1998) did not distinguish between larval and adult ticks or consider phylogenetic differences between host species. Thus, a reevaluation of the classification of ticks as more generalist or more specialist parasites in light of evolutionary and life stage differences is necessary. If ticks are more generalist than previously indicated, they may have an increased chance of transmitting the pathogens they carry to a wider diversity of host species, altering animal populations on a larger scale (Power and Mitchell, 2004), and threatening the survival of small host populations (Altizer et al. 2003). Also, since the transmission of some pathogenic agents can be associated with a particular tick life stage (e.g., tick-borne encephalitis virus, Babesia spp., and the Lyme disease agent Borrelia burgdorferi are preferentially transmitted by juvenile ticks) (Sonenshine, 1993; Ostfeld et al. 1995; Randolph and Storey, 1999), it is important to differentiate the host specificity of juvenile and adult ticks.

Host specificity was classically determined as the number of host species a parasite uses (Lymbery, 1989; Poulin and Mouillot, 2003; Poulin and Keeney, 2007). More recent host specificity indices, however, include ecological characteristics (e.g., prevalence or intensity of parasite infestation; Rohde, 1980, 1993, 2002); evolutionary history, (i.e., host 
taxonomic or phylogenetic distances; Caira et al. 2003; Poulin and Mouillot, 2003); or both (Poulin and Mouillot, 2005). These indices offer deeper insights into differences in host specificity and help to reduce the biases associated with inadequate sampling.

We used a large, newly assembled data set of unusually high quality to re-evaluate the specificity of South African ticks for mammalian hosts. We used this opportunity to both reassess existing knowledge of tick-host specificity in southern Africa and explore the utility of two state-of-the-art host specificity indices. Specifically, we asked (1) whether ticks are dominantly host specialists or host generalists; (2) whether differences in host specificity between juvenile and adult ticks occur; and (3) whether the two host specificity indices, which accounted for (i) host phylogeny and (ii) host phylogeny and tick infestation intensity respectively, would provide the same or different insights and conclusions about the nature of tick-host relationships.

\section{MATERIALS AND METHODS}

\section{Data}

The data were collected by Prof. Ivan Horak (IH) over a 36-year period. Each tick sampled was either pulled off from a dead (natural death, roadkill, hunted) or a living host (domestic species). The animals were not captured or restricted under any circumstances. Data were captured digitally from hand-written notebooks over a two-year period, under the direct supervision of IH; each row of data was individually re-checked post capture for errors. All ticks in the data set were individually identified by $\mathrm{IH}$ and post-identification taxonomic revisions and reclassifications were included in the database, ensuring that both nomenclature and identification were contemporary and consistent throughout the data set. Using 'collection' to refer to samples of one or more ticks of a given species taken from a 
single host, the final data set used in this analysis consisted of 35,604 collections of 61 tick species (from 9 genera of the family Ixodidae) obtained from 95 mammal host species (85 wild mammals and 10 domestic mammals) (Supplementary Material A) collected from 1976 to 2012 in all nine provinces of South Africa.

For each collection, the tick species, life stage (larva, nymph or adult), the number of individual ticks collected, the host species, the host health condition, the geographic location of the sample, and the date of collection were recorded. In some cases, the host species was not known but its genus or family was indicated. All of the hosts considered in this analysis were mammalian. They belonged to 11 orders of mammals: Carnivora (29 spp.), Cetartiodactyla (32 spp.), Rodentia (14 spp), Primates (3 spp.), Perissodactyla (6 spp.), Macroscelidea (4 spp.), Lagomorpha (3 spp.), Proboscidea (1 sp.), Hyracoidean (1 spp.), Eulipotyphla (1 spp.), and Soricomorpha (1 family, Soricidae).

\section{Host specificity indices}

We calculated two different state-of-the-art indices for the data set. The first of these, $S_{\mathrm{TD}}$ (Poulin and Mouillot, 2003), quantifies the specificity of each tick species that parasitized two or more mammal hosts. Low values indicate tick species that primarily infested closely related hosts, while high values reflect tick species that were found across divergent host species. A higher $S_{\mathrm{TD}}$ index indicates a more generalist parasite.

The $S_{\mathrm{TD}}$ index accounts for the number of host species used by the tick species, $S$, and for the divergence time between each pair of host species $i$ and $j, \omega_{i j}$, expressed in millions of years:

$$
S_{\mathrm{TD}}=2 \frac{\sum \sum_{i<j} \omega_{i j}}{S(S-1)}
$$


The variance of the index $S_{\mathrm{TD}}\left(\operatorname{Var}_{\mathrm{TD}}\right)$ was calculated for tick species feeding on a minimum of three host species (it is always zero with two species; Poulin and Mouillot 2003). The $\operatorname{Var} S_{\mathrm{TD}}$ index provides information about the distribution of hosts across the phylogenetic tree. The higher the $\operatorname{Var} S_{\mathrm{TD}}$, the more hosts are evenly distributed across the phylogenetic tree. The variance of the $S_{\mathrm{TD}}$ index was computed as follows:

$$
\operatorname{Var} S_{\mathrm{TD}}=\frac{\sum \sum_{i \neq j}\left(\omega_{i j}-\bar{\omega}\right)^{2}}{S(S-1)}
$$

where $\bar{\omega}$ was the average phylogenetic distance over all pairs of parasitized hosts.

The second index, $S_{\mathrm{TD}} *$ (Poulin and Mouillot, 2005), differs from the first index by its inclusion of abundance data (i.e., the number of ticks of each species collected from each infested host and not just the presence or absence of each tick species such as in Supplementary Material B). Low values indicate that the tick species achieve a high intensity of infestation on a few closely related hosts, while high values reflect tick species that reach their highest intensity of infestation in distantly related host species. The higher the $S_{\mathrm{TD}} *$ index, the more generalist is the parasite. The $S_{\mathrm{TD}} *$ index weights the sum of the phylogenetic distances, $\omega_{i j}$, by the intensity of infestation in host $i\left(I_{i}\right)$ and host $j\left(I_{j}\right)$ :

$$
S_{\mathrm{TD}} *=\frac{\sum \sum_{i<j} \omega_{i j} I_{i} I_{j}}{\sum \sum_{i<j} I_{i} I_{j}}
$$

where $I_{i}$ and $I_{j}$ were calculated as the average number of individual ticks of a given species found on the infested individuals of the host species $i$ and $j$, respectively (Margolis et al. 1982).

The variance of the index $S_{\mathrm{TD}} *\left(\operatorname{Var} S_{\mathrm{TD}} *\right)$ was calculated for tick species feeding on a minimum of three host species. The $\operatorname{Var} S_{\mathrm{TD}} *$ provides information about the distribution of hosts across the phylogenetic tree and the distribution of infestation intensities. The higher 
the $\operatorname{Var} S_{\mathrm{TD}}^{*}$, the more hosts are evenly distributed across the phylogenetic tree and across the distribution of infestation intensity. The variance of $S_{\mathrm{TD}} *$ was computed as follows:

$$
\operatorname{VarS}_{\mathrm{TD}} *=\frac{\sum \sum_{i \neq j}\left[\left(\omega_{i j} I_{i} I_{j}\right)-\left(\overline{\omega_{l J} I_{l} I_{j}}\right)\right]^{2}}{\sum \sum I_{i} I_{j}}
$$

where $\overline{\omega_{l j} I_{l} I_{j}}$ was the average of the $\omega_{i j} \times I_{i} I_{j}$ product.

\section{Phylogenetic data}

The majority of the divergence times between mammal species were obtained from the phylogenetic tree published by Bininda-Emonds et al. (2007). The species of interest were selected and separated from the rest of the tree using the package 'ape 3.1-1' (Paradis et al. 2004) in the $\mathrm{R}$ software 3.1.2. ( $\mathrm{R}$ Core Team, 2014), and the divergence times were visualized with the programme FigTree v1.4.2 (Supplementary Material C). Phylogenetic information for two domestic mammal species (Felis silvestris catus and Bos indicus) was derived from other sources (Driscoll et al. 2007; Hiendleder et al. 2008).

\section{Analyses of indices}

The indices and their variances were computed for three categories of ticks: all ticks (whatever their life stage), juveniles (larva and nymph), and adults. The values of the indices and their variances were tested for normality using Shapiro-Wilks tests and for skewness using D'Agostino skewness tests in the R package 'moments 0.14 '. We tested for differences between juvenile and adult indices using a Wilcoxon signed rank test (Siegel and Castellan Jr., 1998). All calculations and statistical tests were conducted in R 3.1.2. (R Core Team, 2014). 


\section{RESULTS}

\section{Collections vs. host species}

The most-collected ticks came from 50 different host species (Fig. 1). Although the number of host species increased initially with sampling effort, the number of mammal species recorded for each individual tick species reached a plateau beyond about a thousand collections (Fig. 1).

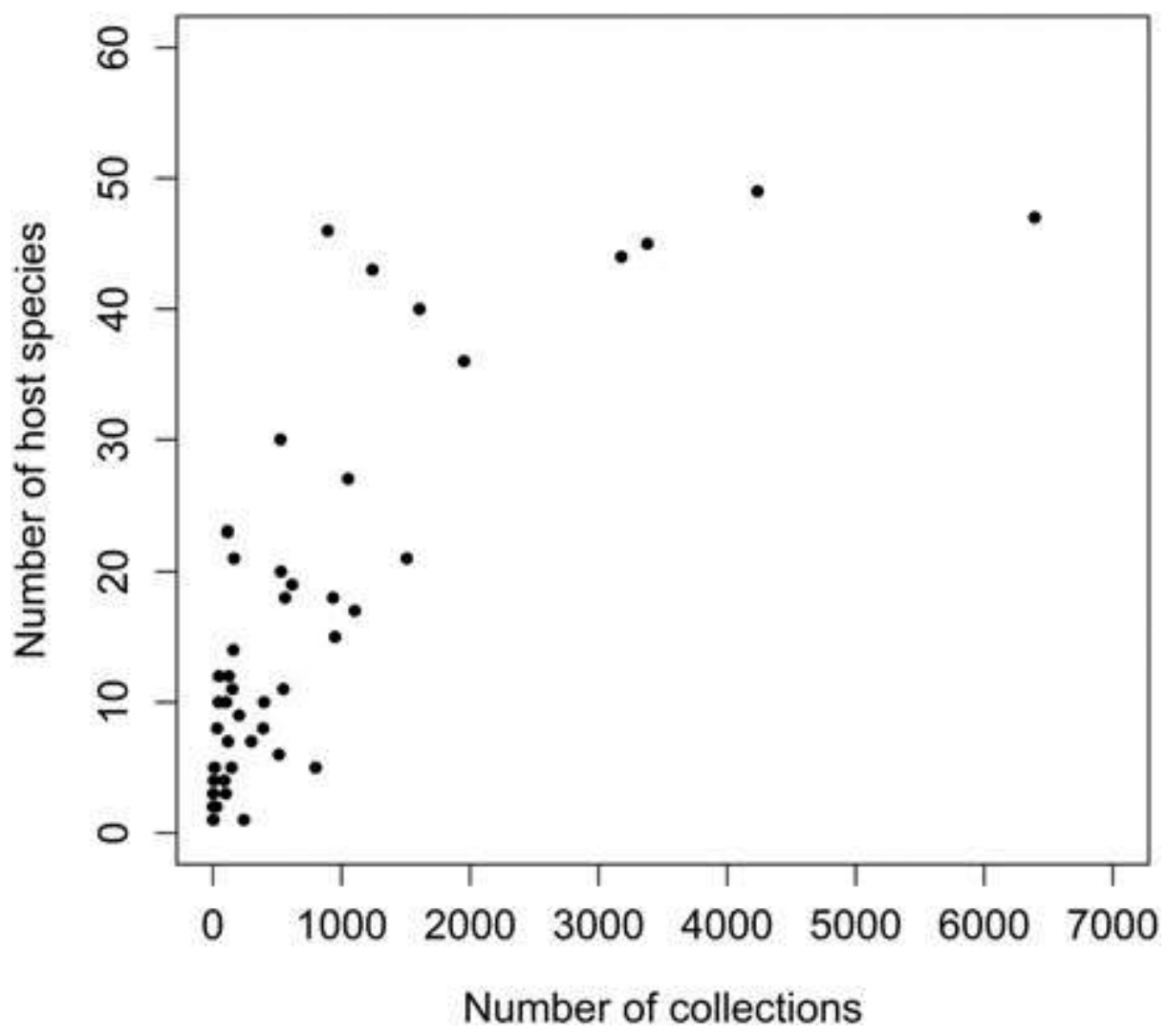

Figure 1. Number of mammalian host species (total $n=95$ species) as a function of the number of collections (total $\mathrm{n}=35,604$ collections) for the 61 recorded tick species. Collections refer to samples of one or more ticks taken from a single host.

\section{Host specificity indices}

The $S_{\mathrm{TD}}$ and $S_{\mathrm{TD}} *$ indices were calculated for 54 of the 61 recorded tick species $(7$ species fed on $<2$ mammal host species and were not included) (Supplementary Material D). 
The $S_{\mathrm{TD}}$ index had a mean value of 70.65 and a median of 71.85 for ticks of all life stages; a mean of 68.72 and a median of 71.41 for juvenile ticks; and a mean of 62.88 and a median of 63.40 for adult ticks. The lowest $S_{\mathrm{TD}}$ index values (most specialised ticks) for pooled life stages and juvenile ticks was found for Amblyomma nuttalli Dönitz, 1909 ( $S_{\mathrm{TD}}=$ 16.80 in both cases), a tick species that commonly parasitizes reptiles. It was collected from two carnivores, Acinonyx jubatus and Panthera leo. The lowest index value for adult ticks was found for Dermacentor rhinocerinus (Denny, 1843) $\left(S_{\mathrm{TD}}=14.70\right)$, which was collected from two rhinoceroces, Ceratotherium simum and Diceros bicornis. The highest $S_{\mathrm{TD}}$ index value (most generalist tick) for pooled life stages and juvenile ticks was found for Amblyomma tholloni Neumann, 1899 (all life stages: $S_{\mathrm{TD}}=97.70$; juvenile ticks: $S_{\mathrm{TD}}=$ 96.10). This tick species was found on three very different hosts when looking at all life stages: Lepus saxatilis, Loxodonta africana and Panthera leo, and on two of these host species (Panthera leo and Lepus saxatilis) when considering juvenile ticks. For adult ticks, the $S_{\mathrm{TD}}$ index was highest for Ixodes bakeri Arthur and Clifford, $1961\left(S_{\mathrm{TD}}=98.50\right)$, which was found on two small mammals: Elephantulus myurus and Otomys sp.. The distribution of the $S_{\mathrm{TD}}$ index was significantly negatively skewed globally $(\mathrm{z}=-2.54, \mathrm{p}=0.01$; Fig.2a) and for juvenile ticks ( $\mathrm{z}=-2.52, \mathrm{p}=0.01$; Fig.2c), indicating that according to this index, the majority of these tick species behaved as generalists. For adult ticks however, the distribution of the $S_{\mathrm{TD}}$ index was not significantly skewed ( $\mathrm{z}=-0.9, \mathrm{p}=0.36$; Fig.2e), suggesting that they do not behave more as generalists than as specialists.

The $S_{\mathrm{TD}} *$ index had a mean value of 65.54 and a median of 70.61 for ticks of all life stages, a mean of 55.24 and a median of 51.99 for juvenile ticks, and a mean of 58.78 and a median of 63.40 for adult ticks. The lowest $S_{\mathrm{TD}} *$ index value (most specialist tick) was again found for Amblyomma nuttalli Dönitz, $1909\left(S_{\mathrm{TD}^{*}}=16.8\right)$ for pooled life stages and 

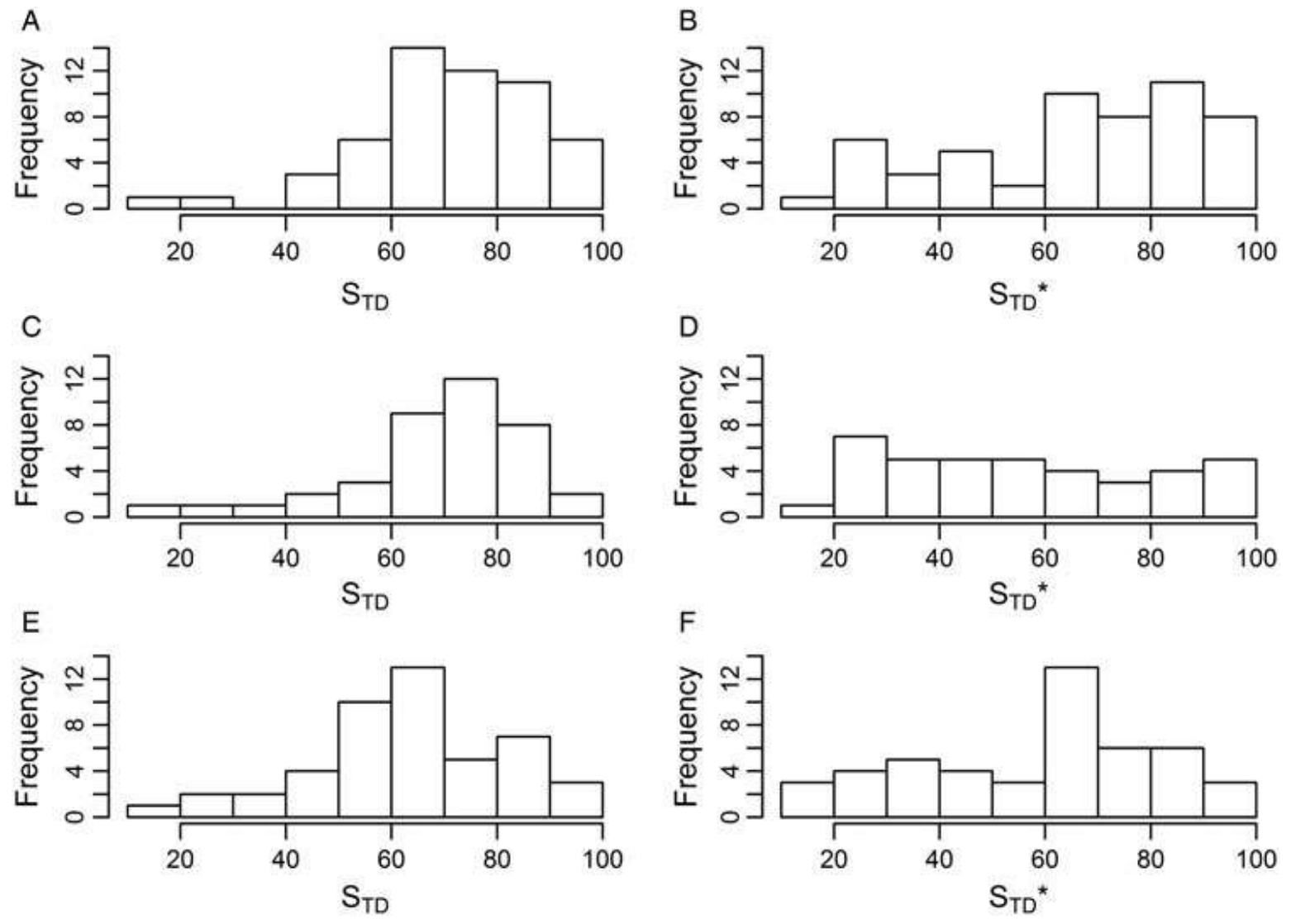

Figure 2. Distribution of the host specificity indices $S_{\mathrm{TD}}$ and $S_{\mathrm{TD}}$ * obtained for all ticks of all life stages (A, B), for juvenile ticks only (C, D), and for adult ticks only (E, F).

juvenile ticks. The lowest index values for adult ticks was again found for Dermacentor rhinocerinus (Denny, 1843) $\left(S_{\mathrm{TD}}=14.70\right)$. The highest $S_{\mathrm{TD}} *$ index value (most generalist tick) for all life stages was found for Amblyomma tholloni Neumann, $1899\left(S_{\mathrm{TD}}{ }^{*}=97.99\right)$, which was collected from Lepus saxatilis, Loxodonta africana and Panthera leo. For juvenile ticks, the $S_{\mathrm{TD}} *$ index was highest for Rhipicephalus distinctus Bedford, 1932 ( $S_{\mathrm{TD}} *$ = 97.06), which was found on ten host species (Caracal caracal, Elephantulus edwardii, Elephantulus myurus, Galerella pulverulenta, Lepus saxatilis, Pedetes capensis, Procavia capensis, Pronolagus rupestris, Rhabdomys pumilio and Saccostomus campestris). For adult ticks, the $S_{\mathrm{TD}} *$ index was highest for Ixodes bakeri Arthur and Clifford, $1961\left(S_{\mathrm{TD}}=\right.$ 
98.74), which was found on Elephantulus myurus and Otomys sp.. The distribution of the $S_{\mathrm{TD}} *$ index was not significantly skewed (all: $\mathrm{z}=-1.46, \mathrm{p}=0.14$; juveniles: $\mathrm{z}=0.78, \mathrm{p}=$ 0.43; adults: $\mathrm{z}=-0.76, \mathrm{p}=0.44$; Fig. $2 \mathrm{~b}, 2 \mathrm{~d}, 2 \mathrm{f}$ ), indicating that according to this index and across all life stages, ticks do not behave more as specialists than as generalists, and that all degrees of host specificity are observed (Fig. 2).

\section{Variance of host specificity indices}

The variances of each index were calculated for 42 tick species (all life stages), 36 species in their juvenile stage and 36 species in their adult stage. The $\operatorname{Var} S_{\mathrm{TD}}$ and $\operatorname{Var} S_{\mathrm{TD}}{ }^{*}$ values exhibited a high frequency of small values, whether for all ticks, juveniles only, or adults
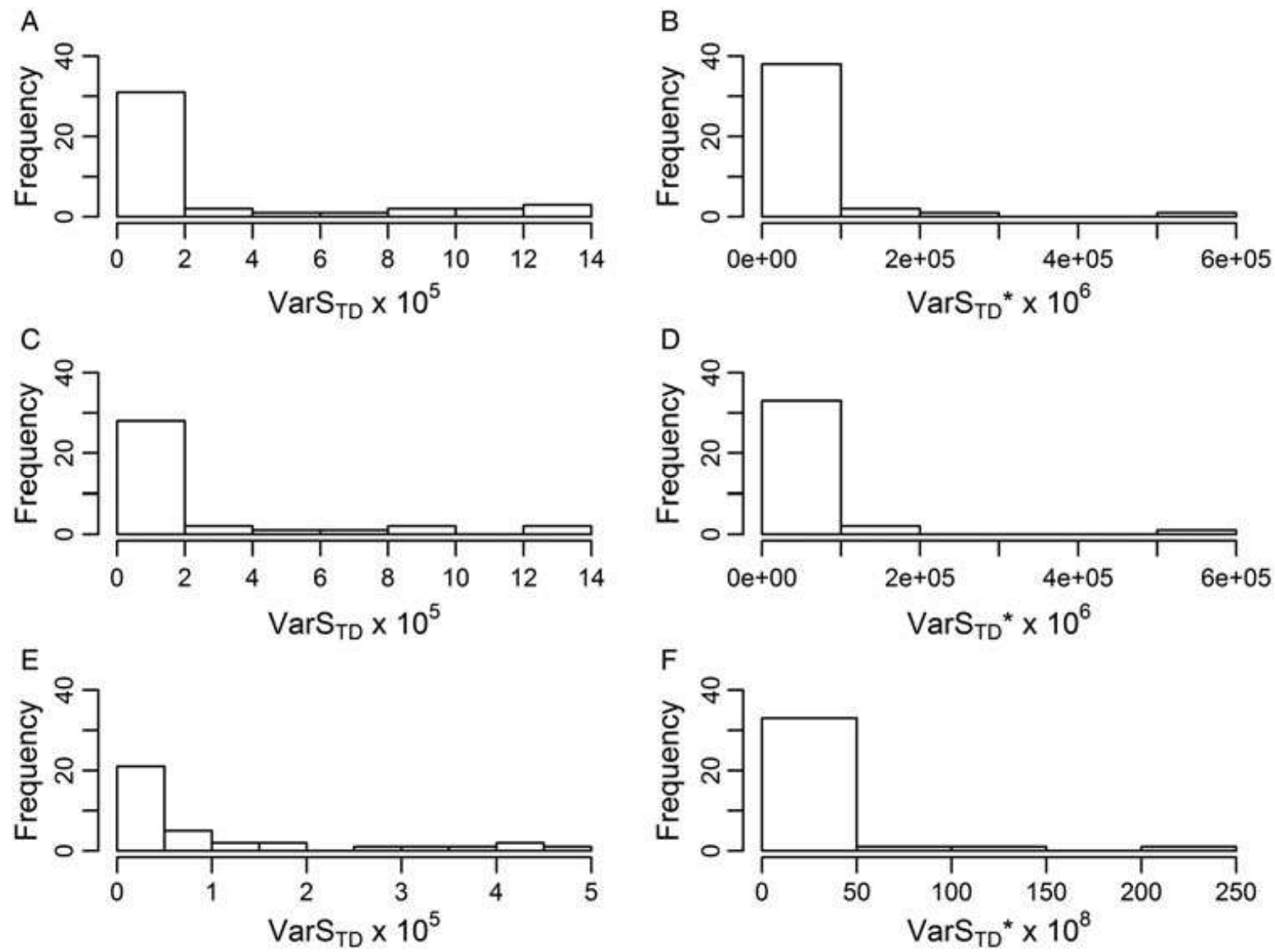

Figure 3. Distribution of $\operatorname{Var}_{\mathrm{TD}}$ and $\operatorname{Var} S_{\mathrm{TD}} *$ obtained for all ticks of all life stages (A, B), for juvenile ticks only (C,D), and for adult ticks (E,F). 
only (Fig. 3). There was thus little taxonomic heterogeneity among groups of host species and little heterogeneity in the intensity of infestation among hosts (Fig. 3).

\section{Comparison of host specificity indices for juvenile and adult ticks}

$S_{\mathrm{TD}}$ and $S_{\mathrm{TD}} *$ values for adult ticks followed a normal distribution, but those for juvenile ticks did not. A non-parametric Wilcoxon signed rank test was thus used to compare the values of the two life-stages. Significant differences were found between them for $S_{\mathrm{TD}}(\mathrm{V}=$ 486, $\mathrm{p}=0.001$ ), with juvenile ticks having higher $S_{\mathrm{TD}}$ values than adults (Fig. $4 \mathrm{a}$ ). Conversely, the $S_{\mathrm{TD}} *$ values of adult and juvenile ticks were not significantly different $(\mathrm{V}=$ 294, p = 0.74) (Fig. 4b).

A

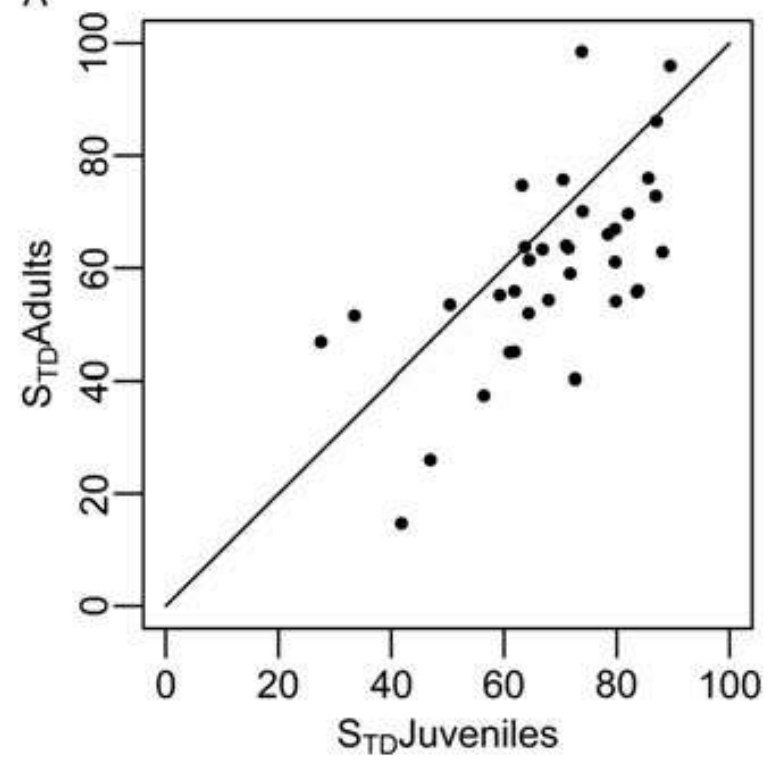

B

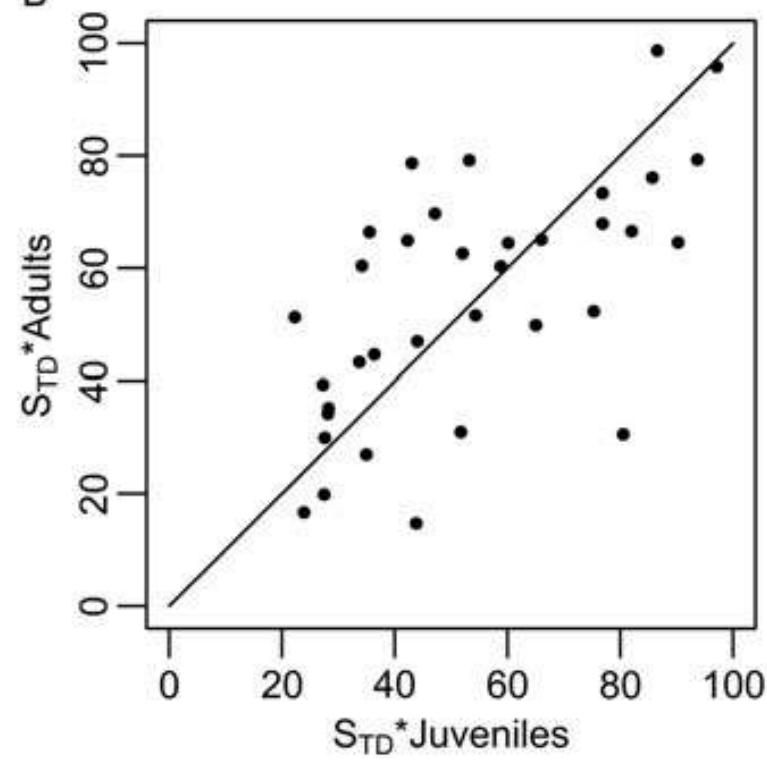

Figure 4. Relationship between the host specificity of juvenile and adult ticks, using the $S_{\mathrm{TD}}$ index (A) and the $S_{\mathrm{TD}} *$ index (B). The solid line represents the expected relationship if juveniles' and adults' values are similar. 


\section{DISCUSSION}

Accounting for host phylogeny using the $S_{\mathrm{TD}}$ index (Poulin and Mouillot, 2003), we found that across all life stages, most ticks behaved as generalists; and that juvenile ticks tended to be more generalist than their adults. By contrast, when the intensity of tick infestation was accounted for using the $S_{\mathrm{TD}} *$ index (Poulin and Mouillot, 2005), tick species were not found to be more generalist than specialist and both adults and juveniles exhibited a wide range of specificity for mammal species.

The results of our analysis are broadly in support of the results obtained by Cumming (1998) for his pan-African analysis across all host taxonomic groups. Cumming (1998) included a number of more specialised species on reptiles and birds that were not included in this analysis; incorporation of these data into a comparable analysis would probably reduce the degree of host generalism that we found in our analysis, although the potential for some species to be found across classes (e.g., on both birds and reptiles) might have the converse effect.

Our finding that juvenile ticks tend to be more generalist than their adults is novel. This is also the first time that the evolutionary host-parasite relationship (Poulin and Mouillot, 2003) has been considered in assessing tick-host specificity in Africa. According to the $S_{\mathrm{TD}}$ index, ticks in South Africa can infest a variety of hosts with distant divergence times (i.e., high $S_{\mathrm{TD}}$ index values). This suggests that some tick species have made relatively long jumps across their hosts' phylogenetic tree (Cumming, 2000). However, the low VarS $S_{\mathrm{TD}}$ values also showed that the host distribution was homogenous in the phylogenetic tree for most ticks, implying that the majority of tick species at any life stage tended to infest host species with similar divergence time distributions across the phylogenetic tree. 
The $S_{\mathrm{TD}}$ index shows that juvenile ticks behave more as generalists than adult ticks. In general, juvenile ticks appear to be able to infest host species from different phylogenetic groups, becoming more host-specific as adults. Some tick species (e.g., Rhipicephalus exophthalmos Keirans and Walker, 1993; Rhipicephalus capensis Koch, 1844; Hyalomma glabrum Delpy, 1949; and Dermacentor rhinocerinus (Denny, 1843)) exhibited a large decrease in $S_{\mathrm{TD}}$ values from juvenile to adult stages, denoting an important change of strategy from generalist to specialist during their lifetime. This shift may be mediated by mouthpart morphology; juvenile ticks are unable to pierce the hide of most large mammals and must feed on thinner-skinned organisms. The need to find a mate may also impose greater specificity on adults. Experimental studies also suggest that juvenile ticks have low levels of specificity (Oliver, 1989; James and Oliver, 1990; Belan and Bull, 1995; Marques Lisbôa Lopes et al. 1998) and the juveniles of many species can be reared successfully on domestic rabbits. In South Africa, the larvae and nymph of ixodid tick species are typically found on small mammals, but these juvenile ticks have also been found on a large variety of domestic and wild animal species (Horak et al. 2000). These findings stress the need to consider the different life stages of the vectors in the study of tick-borne diseases. Considering only adult ticks may lead to an important under-estimation of pathogen transmission rates and/or of the range of hosts at risk. For example, Rickettsia africae, the causal agent of African tick bite fever, is transmitted by Amblyomma larvae and nymphs that infest a broader host range (including domestic and wild mammals, humans, as well as reptiles and birds) than Amblyomma adults (Cumming, 1998; Jensenius et al. 2003).

Using the $S_{\mathrm{TD}} *$ index (Poulin and Mouillot, 2005), different results were obtained for tick host specificity in South Africa. Adding infestation intensity to host phylogenetic distinctness lowered the values of the specificity index and led to a non-skewed distribution 
of specificity degrees. Contrary to what was found using the $S_{\mathrm{TD}}$ index, this index indicates that ticks were neither more generalists nor more specialists. This result differs from that of Nava and Guglielmone (2013) for neotropical ixodid ticks of wild and domestic hosts (mammals, birds, amphibians and reptiles), who found that juvenile ticks fed on a broader taxonomic range of hosts and exhibited higher $S_{\mathrm{TD}} *$ values than adults. The difference between their study and ours may be attributable to differences in host species diversity and/or phenology and in the measure of host exploitation by the ticks (prevalence, i.e., presence-absence, $v s$ infestation intensity).

As with the first index, $\operatorname{Var} S_{\mathrm{TD}} *$ values were low at any life stage, suggesting that the majority of tick species infested more intensively host species with similar phylogenetic distances. Poulin and Mouillot (2004) similarly found a negative correlation between parasites' average infection success and the taxonomic or phylogenetic distances among their hosts. These authors argued that a parasite may reach a higher abundance in congeneric hosts because of shared host features (e.g. immune system, behaviour, anatomy, biochemistry) to which it is pre-adapted, whilst colonizing distantly related hosts requires parasite physiological and morphological adaptations that may affect its ability to achieve a high abundance.

Together, our results suggest that ticks are generalist, but do not infest with the same intensity hosts that are phylogenetically too distant (as revealed by the $S_{\mathrm{TD}}$ and the $S_{\mathrm{TD}} *$ indices, respectively). Although host phylogenetic distinctness denotes host switching over evolutionary time scales (Poulin and Mouillot, 2003; Poulin and Mouillot, 2004), considering infestation intensity emphasizes host use more strongly (Poulin and Mouillot, 2005). 
Despite the more sophisticated conclusions about tick feeding preferences offered by the inclusion of both phylogeny and infestation intensity, incorporating these elements in the analyses requires data of good quality. It is difficult to accurately estimate the number of ticks on a host. For example, when studying heavily infested animals, special attention is given to a fixed area (i.e., ears, neck and head) (Sonenshine, 1993); orifices, such as the rectum and ear cavities, are hard to search effectively on a live animal. Ticks may also attach to their hosts only at particular times during their life cycle (Jongejan and Uilenberg, 2004); and microclimatic conditions may influence when either a juvenile or adult tick may be found on a particular host (Randolph and Storey, 1999).

We conclude that although ticks as a group appeared to follow a range of strategies from specialist to generalist, a majority of tick species behaved as generalist when feeding on mammals in South Africa and that for many tick species, generalism was higher during the juvenile stage. The separation of different life history stages and the inclusion of evolutionary and ecological data using two state-of-the-art indices provided new insights into tick-mammal interactions. Our results also demonstrate the value of comparing different host specificity indices, while indicating that further research is needed to determine their sensitivity to data type and quantity.

\section{ACKNOWLEDGMENTS}

We thank Rina Serfontein and her many assistants for their role in data capture, and Lisa Nupen for assisting with the processing of phylogenetic information. 


\section{FINANCIAL SUPPORT}

This research was supported by a grant from the South African National Biodiversity Institute's South African Biodiversity Information Facility (SABIF) and the DST/NRF Centre of Excellence at the Percy FitzPatrick Institute.

\section{REFERENCES}

Altizer, S., Harvell, D. and Friedle, E. (2003). Rapid evolutionary dynamics and disease threats to biodiversity. Trends in Ecology and Evolution 18, 589-596. doi:10.1016/j.tree.2003.08.013.

Belan, I. and Bull, C. M. (1995). Host-seeking behaviour by Australian ticks (Acari: Ixodidae) with differing host specificities. Experimental \& Applied Acarology 19, 221-232. doi: 10.1007/BF00130825.

Bininda-Emonds, O. R. P., Cardillo, M., Jones, K. E., MacPhee, R. D. E., Beck, R. M. D., Grenyer, R., Price, S. A., Vos, R. A., Gittleman, J. L. and Purvis, A. (2007). The delayed rise of present-day mammals. Nature 446, 507-512. doi: 10.1038/nature05634.

Caira, J. N., Jensen, K. and Holsinger, K. E. (2003). On a new index of host specificity. In Taxonomy, ecology and evolution of metazoan parasites (ed. Combes, C. and Jourdane, J.), pp 161-201. University of Perpignan Press, Perpignan, France.

Cumming, G. S. (1998). Host preference in African ticks (Acari: Ixodida): a quantitative data set. Bulletin of Entomological Research 88, 379-406. doi: 10.1017/S0007485300042139.

Cumming, G. S. (2000). Host use does not clarify the evolutionary history of African ticks (Acari: Ixodoidea). African Zoology 35, 43-50. doi: 10.1080/15627020.2000.11407190. 
Cumming, G. S. (2004). On the relevance of abundance and spatial pattern for interpretations of host-parasite association data. Bulletin of Entomological Research 94, 401-409. doi: 10.1079/BER2004319.

Cumming, G.S. and Van Vuuren, D. P. (2006). Will climate change affect ectoparasite species ranges?. Global Ecology and Biogeography 15, 486-497. doi: 10.1111/j.1466822x.2006.00241.x.

Driscoll, C. A., Menotti-Raymond, M., Roca, A. L., Hupe, K., Johnson, W. E., Geffen, E., Harley, E. H., Delibes, M., Pontier, D., Kitchener, A. C., Yamaguchi, N., O'Brien, S. J. and Macdonald, D. W. (2007). The Near Eastern origin of cat domestication. Science 317, 519-523. doi: 10.1126/science.1139518.

Hiendleder, S., Lewalski, H. and Janke, A. (2008). Complete mitochondrial genomes of Bos taurus and Bos indicus provide new insights into intra-species variation, taxonomy and domestication. Cytogenetic and Genome Research 120, 150-156. doi: 10.1159/000118756

Hoogstraal, H. and Aeschlimann, A. (1982). Tick-host specificity. Bulletin de la Société Entomologique Suisse 55, 5-32.

Hoogstraal, H. and Kim, K. C. (1985). Tick and mammal coevolution, with emphasis on Haemaphysalis. In Coevolution of Parasitic Arthropods and Mammals (ed. Kim, K. C.), pp 505-568. Wiley \& Sons, New York.

Hoogstraal, H., Clifford, C. M. and Keirans, J. E. (1973). Argas (Microargas) transversus (Ixodoidea: Argasidae) of Galapagos giant tortoises: description of the female and nymph. Annals of the Entomological Society of America 66, 727-732. doi: http://dx.doi.org/10.1093/aesa/66.4.727. 
Horak, I. G., Braack, L. E., Fourie, L. J. and Walker, J. B. (2000). Parasites of domestic and wild animals in South Africa. XXXVIII. Ixodid ticks collected from 23 wild carnivore species. The Onderstepoort Journal of Veterinary Research 67, 239-250.

James, A. and Oliver, J. H. (1990). Feeding and host preference of immature Ixodes dammini, I. scapularis, and I. pacificus (Acari: Ixodidae). Journal of Medical Entomology 27, 324-330. doi: 10.1093/jmedent/27.3.324 324-330.

Jensenius, M., Fournier, P., Kelly, P., Myrvang, B. and Raoult, D. (2003). African tick bite fever. The Lancet Infectious Diseases 3, 557-564. doi: 10.1016/S1473-3099(03)007394.

Jongejan, F. and Uilenberg, G. (2004). The global importance of ticks. Parasitology 129, S3-S14. doi: : 10.1017/S0031182004005967.

Karesh, W. B., Cook, R. A., Bennett, E. L. and Newcomb, J. (2005). Wildlife trade and global disease emergence. Emerging Infectious Diseases 11, 1000-1002.

Klompen, J. S. H., Black, W. C., Keirans, J. E. and Oliver Jr., J. H. (1996). Evolution of ticks. Annual Review of Entomology 41, 141-161. doi: 10.1146/annurev.en.41.010196.001041.

Koh, L. P., Dunn, R. R., Sodhi, N. S., Colwell, R. K., Proctor, H. C. and Smith, V. S. (2004). Species coextinctions and the biodiversity crisis. Science 305, 1632-1634. doi: 10.1126/science. 1101101 .

Lymbery, A. J. (1989). Host specificity, host range and host preference. Parasitology Today 5, 298.

Margolis, L., Esch, G. W., Holmes, J. C., Kuris, A. M. and Schad, G. A. (1982). The use of ecological terms in parasitology (report of an ad hoc committee of the American society of parasitologists). Journal of Parasitology 68, 131-133. doi: 10.2307/3281335. 
Marques Lisbôa Lopes, C., Cerequeira Leite, R., Bahia Labruna, M., de Oliveira, P. R., Miranda Ferreira Borges, L., Batista Rodrigues, Z., Avila de Carvalho, H., Vianna de Freitas, C. M. and Vieira Junior, C. R. (1998). Host specificity of Amblyomma cajennense (Fabricius, 1787) (Acari: Ixodidae) with Comments on the drop-off rhythm. Memorias Do Instituto Oswaldo Cruz 93, 347-351. doi: 10.1590/S007402761998000300014.

Moyo, B. and Masika, P. J. (2009). Tick control methods used by resource-limited farmers and the effect of ticks on cattle in rural areas of the Eastern Cape Province, South Africa. Tropical Animal Health and Production 41, 517-523. doi: 10.1007/s11250-008$9216-4$.

Muchenje, V., Dzama, K., Chimonyo, M., Raats, J. G. and Strydom, P. E. (2008). Tick susceptibility and its effects on growth performance and carcass characteristics of Nguni, Bonsmara, and Angus steers raised on natural pasture. Animal 2, 298-304. doi: 10.1017/S1751731107001036.

Nava, S. and Guglielmone, A. A. (2013). A meta-analysis of host specificity in Neotropical hard ticks (Acari: Ixodidae). Bulletin of Entomological Research 103, 216224. doi: $10.1017 /$ S0007485312000557.

Oliver, J. H. (1989). Biology and systematics of ticks (Acari: Ixodida). Annual Review of Ecology and Systematics 20, 397-430.

Ostfeld, R. S., Cepeda, O. M., Hazler, K. R. and Miller, M. C. (1995). Ecology of Lyme disease: habitat associations of ticks (Ixodes scapularis) in a rural landscape. Ecological Applications 5, 353-361. doi: 10.2307/1942027.

Paradis, E., Claude, J. and Strimmer, K. (2004). APE: Analyses of phylogenetics and evolution in R language. Bioinformatics 20, 289-290. doi: 10.1093/bioinformatics/btg412. 
Petney, T. N., Kolonin, G. V. and Robbins, R. G. (2007). Southeast Asian ticks (Acari: Ixodida): a historical perspective. Parasitology research 101, 201-205. doi: 10.1007/s00436-007-0687-4.

Poulin, R. and Mouillot, D. (2003). Parasite specialization from a phylogenetic perspective: a new index of host specificity. Parasitology 126, 473-480. doi: 10.1017/S0031182003002993.

Poulin, R. and Mouillot, D. (2004). The relationship between specialization and local abundance: the case of helminth parasites of birds. Oecologia 140, 372-378. doi: 10.1007/s00442-004-1593-4.

Poulin, R. and Mouillot, D. (2005). Combining phylogenetic and ecological information into a new index of host specificity. Journal of Parasitology 91, 511-514. doi: 10.1645/GE-398R.

Poulin, R. and Keeney, D. B. (2007). Host specificity under molecular and experimental scrutiny. Trends in Parasitology 24, 24-28. doi: 10.1016/j.pt.2007.10.002.

Power, A. G. and Mitchell, C. E. (2004). Pathogen spillover in disease epidemics. The American Naturalist 164, S79-S89. doi: 10.1086/424610.

R Development Core Team (2014). R: A language and environment for statistical computing. R Foundation for Statistical Computing, Vienna, Austria.

Randolph, S. E. and Storey, K. (1999). Impact of microclimate on immature tick-rodent host interactions (Acari: Ixodidae): implications for parasite transmission. Journal of Medical Entomology 36, 741-748. doi: http://dx.doi.org/10.1093/jmedent/36.6.741

Rohde, K. (1980). Host specificity indices of parasites and their application. Experientia 36, 1369-1371. doi: 10.1007/BF01960103.

Rohde, K. (1993). Ecology of Marine Parasites. CAB International, Wallingford, U.K. 
Rohde, K. (2002). Ecology and biogeography of marine parasites. Advances in Marine Biology 43, 1-86. doi: 10.1016/S0065-2881(02)43002-7.

Siegel, S. and Castellan Jr., N. J. (1998). The case of one sample, two measures or paired replicates. In Nonparametric statistic for the behavioral sciences (ed. Siegel, S. and Castellan Jr., N. J.), pp 87-95. McGraw Hill, New York.

Sonenshine, D. E. (1991). Introduction. In Biology of ticks, pp 3-12. Oxford University Press, New York.

Sonenshine, D. E. (1993). Tick-borne and tick-caused diseases. In Biology of ticks, pp 107-330. Oxford University Press, New York.

Stone, B. F., Binnington, K. C., Gauci, M. and Aylward, J. H. (1989). Tick/host interactions for Ixodes holocyclus: Role, effects, biosynthesis and nature of its toxic and allergenic oral secretions. Experimental and Applied Acarology 7, 59-69. doi: 10.1007/BF01200453.

Uilenberg, G. (1995). International collaborative research: significance of tick-borne hemoparasitic diseases to world animal health. Veterinary Parasitology 57, 19-41. doi: 10.1016/0304-4017(94)03107-8. 


\section{Supplementary Material}

Supplementary Material A. Mammal host species, their scientific names, common names and type of animal (wild or domestic). The term "domestic" refers to animal species that are dependent on or associated with humans to survive. The term "wild" refers to animal species that do not depend on humans and live in their natural environments. When the host species was not known, its genus or family was indicated.

\begin{tabular}{|c|c|c|c|}
\hline Scientific name & Common name & Mammalian family & Type \\
\hline Acinonyx jubatus & Cheetah & Felidae & wild \\
\hline Aepyceros melampus & Impala & Bovidae & wild \\
\hline Aethomys chrysophilus & Red rock rat & Muridae & wild \\
\hline Aethomys namaquensis & Namaqua rock rat & Muridae & wild \\
\hline Alcelaphus buselaphus & Hartebeest & Bovidae & wild \\
\hline Antidorcas marsupialis & Springbok & Bovidae & wild \\
\hline Atelerix frontalis & Southern African hedgehog & Erinaceidae & wild \\
\hline Bos indicus & Zebu & Bovidae & domestic \\
\hline Bos sp. & Bovine & Bovidae & domestic \\
\hline Bos taurus & Cattle & Bovidae & domestic \\
\hline Canis lupus familiaris & Domestic dog & Canidae & domestic \\
\hline Canis mesomelas & Black-backed jackal & Canidae & wild \\
\hline Capra hircus & Goat & Bovidae & domestic \\
\hline Caracal caracal & Caracal & Felidae & wild \\
\hline Cephalophus natalensis & Red forest duiker & Bovidae & wild \\
\hline Ceratotherium simum & White rhinoceros & Rhinocerotidae & wild \\
\hline Chlorocebus aethiops & Vervet monkey & Cercopithecidae & wild \\
\hline Civettictis civetta & African civet & Viverridae & wild \\
\hline Connochaetes gnou & Black wildebeest & Bovidae & wild \\
\hline
\end{tabular}




\begin{tabular}{|c|c|c|c|}
\hline Connochaetes taurinus & Blue wildebeest & Bovidae & wild \\
\hline Crocuta crocuta & Spotted hyena & Hyaenidae & wild \\
\hline Cynictis penicillata & Yellow mongoose & Herpestidae & wild \\
\hline Damaliscus lunatus & Common tsessebe & Bovidae & wild \\
\hline Damaliscus pygargus & Bontebok & Bovidae & wild \\
\hline Diceros bicornis & Black rhinoceros & Rhinocerotidae & wild \\
\hline Elephantulus brachyrhynchus & Short-snouted elephant shrew & Macroscelididae & wild \\
\hline Elephantulus edwardii & Cape elephant shrew & Macroscelididae & wild \\
\hline Elephantulus myurus & Eastern rock elephant shrew & Macroscelididae & wild \\
\hline Equus asinus & Donkey & Equidae & domestic \\
\hline Equus burchelli & Plains zebra & Equidae & wild \\
\hline Equus caballus & Horse & Equidae & domestic \\
\hline Equus zebra & Mountain zebra & Equidae & wild \\
\hline Felis silvestris catus & Domestic cat & Felidae & domestic \\
\hline Felis nigripes & Black-footed cat & Felidae & wild \\
\hline Felis silvestris cafra & Southern African wild cat & Felidae & wild \\
\hline Galerella pulverulenta & Cape gray mongoose & Herpistidae & wild \\
\hline Galerella sanguinea & Slender mongoose & Herpistidae & wild \\
\hline Genetta genetta & Common genet & Viverridae & wild \\
\hline Genetta sp. & Genets & Viverridae & wild \\
\hline Genetta tigrina & Cape genet & Viverridae & wild \\
\hline Giraffa camelopardalis & Giraffe & Giraffidae & wild \\
\hline Hippotragus equinus & Roan antelope & Bovidae & wild \\
\hline Hippotragus niger & Sable antelope & Bovidae & wild \\
\hline Hystrix africaeaustralis & Cape porcupine & Hystricidae & wild \\
\hline Ichneumia albicauda & White-tailed mongoose & Herpestidae & wild \\
\hline Ictonyx striatus & Striped polecat & Mustelidae & wild \\
\hline Lemniscomys rosalia & Single-striped grass mouse & Muridae & wild \\
\hline
\end{tabular}




\begin{tabular}{|c|c|c|c|}
\hline Leptailurus serval & Serval & Felidae & wild \\
\hline Lepus capensis & Cape hare & Leporidae & wild \\
\hline Lepus saxatilis & Scrub hare & Leporidae & wild \\
\hline Loxodonta africana & African bush elephant & Elephantidae & wild \\
\hline Lycaon pictus & Wild dog & Canidae & wild \\
\hline Macroscelides proboscideus & Round-eared elephant shrew & Macroscelididae & wild \\
\hline Mastomys coucha & Southern multimammate mouse & Muridae & wild \\
\hline Mastomys natalensis & Natal multimammate mouse & Muridae & wild \\
\hline Mellivora capensis & Honey badger & Mustelidae & wild \\
\hline Mungos mungo & Banded mongoose & Herpestidae & wild \\
\hline Neotragus moschatus & Suni & Bovidae & wild \\
\hline Oreotragus oreotragus & Klipspringer & Bovidae & wild \\
\hline Oryx gazella & Gemsbok & Bovidae & wild \\
\hline Otocyon megalotis & Bat-eared fox & Canidae & wild \\
\hline Otolemur crassicaudatus & Brown greater galago & Galagidae & wild \\
\hline Otomys occidentalis & Western Vlei Rat & Muridae & wild \\
\hline Otomys sp. & Vlei rat & Muridae & wild \\
\hline Ovis aries & Sheep & Bovidae & domestic \\
\hline Panthera leo & Lion & Felidae & wild \\
\hline Panthera pardus & Leopard & Felidae & wild \\
\hline Papio hamadryas & Hamadryas baboon & Cercopithecidae & wild \\
\hline Parahyaena brunnea & Brown hyaena & Hyaenidae & wild \\
\hline Pedetes capensis & South African springhare & Pedetidae & wild \\
\hline Pelea capreolus & Grey rhebok & Bovidae & wild \\
\hline Phacochoerus africanus & Warthog & Suidae & wild \\
\hline Potamochoerus larvatus & Bushpig & Suidae & wild \\
\hline Praomys sp. & Mouse & Muridae & wild \\
\hline Procavia capensis & Rock hyrax & Procaviidae & wild \\
\hline
\end{tabular}




\begin{tabular}{|c|c|c|c|}
\hline Pronolagus rupestris & Smith's red rock hare & Leporidae & wild \\
\hline Proteles cristatus & Aardwolf & Hyaenidae & wild \\
\hline Raphicerus campestris & Steenbok & Bovidae & wild \\
\hline Raphicerus melanotis & Cape grysbok & Bovidae & wild \\
\hline Rattus rattus & Black rat & Muridae & domestic \\
\hline Redunca arundinum & Southern reedbuck & Bovidae & wild \\
\hline Redunca fulvorufula & Mountain reedbuck & Bovidae & wild \\
\hline Rhabdomys pumilio & Four-striped grass mouse & Muridae & wild \\
\hline Rhynchogale melleri & Meller's mongoose & Herpestidae & wild \\
\hline Saccostomus campestris & South African pouched mouse & Nesomyidae & wild \\
\hline Soricidae & Shrew & Soricidae & wild \\
\hline Suricata suricatta & Meerkat & Herpestidae & wild \\
\hline Sylvicapra grimmia & Common duiker & Bovidae & wild \\
\hline Syncerus caffer & African buffalo & Bovidae & wild \\
\hline Tatera leucogaster & Bushveld gerbil & Muridae & wild \\
\hline Taurotragus oryx & Common eland & Bovidae & wild \\
\hline Tragelaphus angasii & Nyala & Bovidae & wild \\
\hline Tragelaphus scriptus & Bushbuck & Bovidae & wild \\
\hline Tragelaphus strepsiceros & Greater kudu & Bovidae & wild \\
\hline Vulpes chama & Cape fox & Canidae & wild \\
\hline
\end{tabular}


Supplementary Material B. Tick species distribution among mammal host species: + and - refers to the presence or absence of a tick species on a determined mammal host species respectively.

\begin{tabular}{|c|c|c|c|c|c|c|c|c|c|c|c|c|c|c|c|c|c|c|c|c|c|c|c|c|c|c|c|c|c|c|c|}
\hline \multirow{2}{*}{ Mammal host species } & \multicolumn{31}{|c|}{ Tick species* } \\
\hline & 1 & 2 & 3 & 4 & 5 & 6 & 7 & 8 & 9 & 10 & 11 & 12 & 13 & 14 & 15 & 16 & 17 & 18 & 19 & 20 & 21 & 22 & 23 & 24 & 25 & 26 & 27 & 28 & 29 & 30 & 31 \\
\hline Acinonyx jubatus & + & + & + & - & - & - & - & - & - & + & - & - & - & - & - & + & - & - & + & - & - & - & - & - & - & - & - & - & - & - & - \\
\hline Aepyceros melampus & + & + & - & - & - & - & + & - & - & + & - & - & - & - & - & - & - & - & + & - & - & - & - & - & - & - & - & - & - & - & - \\
\hline Aethomys chrysophilus & - & - & - & - & - & + & - & - & - & + & - & - & - & - & - & - & - & - & + & - & - & - & - & - & - & - & - & - & - & - & - \\
\hline Aethomys namaquensis & - & - & - & - & - & - & - & - & - & + & - & - & - & - & - & - & - & - & - & - & - & - & - & - & - & - & - & - & - & - & - \\
\hline Alcelaphus buselaphus & - & - & - & - & - & - & - & - & - & - & - & - & - & - & - & - & - & - & - & - & - & - & - & - & - & - & - & - & - & - & - \\
\hline Antidorcas marsupialis & - & + & - & - & - & - & - & - & - & - & - & - & - & - & - & - & + & + & + & - & - & - & - & - & - & - & + & - & + & + & - \\
\hline Atelerix frontalis & - & + & - & - & - & - & - & + & - & - & - & - & - & - & - & + & - & - & - & - & - & - & - & - & - & - & - & - & - & - & - \\
\hline Bos sp. & - & - & - & - & - & - & - & - & - & - & - & - & - & - & - & - & - & + & - & - & - & - & - & - & - & - & - & - & - & - & - \\
\hline Bos taurus & + & - & - & - & - & - & - & - & - & - & - & - & - & + & - & - & - & + & + & - & - & - & - & - & - & - & - & - & - & - & - \\
\hline Canis lupus familiaris & + & + & - & - & - & - & + & - & - & + & - & - & - & + & + & + & - & - & + & - & - & - & + & + & - & - & + & + & + & - & - \\
\hline Canis mesomelas & + & + & - & - & - & - & - & - & - & + & - & - & - & + & + & + & - & - & - & - & - & - & - & - & - & - & + & - & + & - & + \\
\hline Capra hircus & + & + & - & - & - & - & - & - & - & + & - & - & - & + & - & - & - & + & + & + & - & - & - & - & - & - & + & - & + & - & - \\
\hline
\end{tabular}


Caracal caracal

Cephalophus natalensis

Ceratotherium simum

Chlorocebus aethiops

Civettictis civetta

Connochaetes gnou

Connochaetes taurinus

Crocuta crocuta

Cynictis penicillata

Damaliscus lunatus

Damaliscus pygargus

Diceros bicornis

Elephantulus brachyrhynchus

Elephantulus edwardii

Elephantulus myurus

Equus asinus

Equus burchelli

Equus caballus

Equus zebra
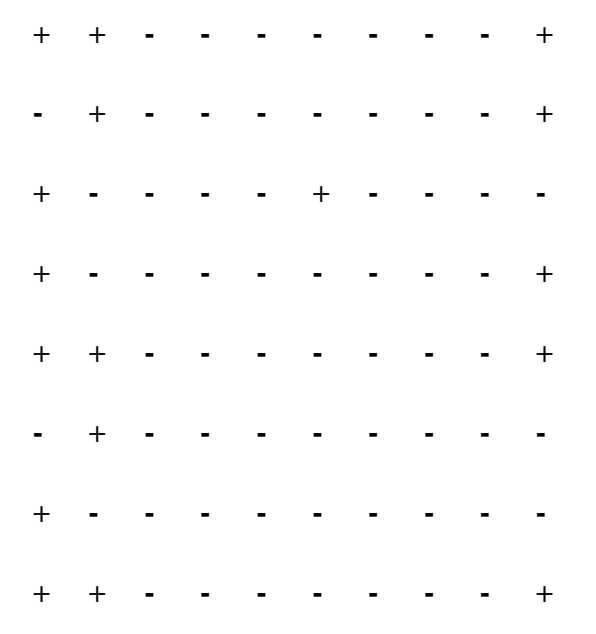

$$
+
$$

$+$


Felis catus

Felis nigripes

Felis silvestris

Galerella pulverulenta

Galerella sanguinea

Genetta genetta

Genetta sp.

Genetta tigrina

Giraffa camelopardalis

Hippotragus equinus

Hippotragus niger

Hystrix africaeaustralis

Ichneumia albicauda

Ictonyx striatus

Lemniscomys rosalia

Leptailurus serval

Lepus capensis

Lepus saxatilis

Loxodonta africana 
Lycaon pictus

Macroscelides proboscideus

Mastomys coucha

Mastomys natalensis

Mellivora capensis

Mungos mungo

Neotragus moschatus

Oreotragus oreotragus

Oryx gazella

Otocyon megalotis

Otolemur crassicaudatus

Otomys occidentalis

Otomys sp.

Ovis aries

Panthera leo

Panthera pardus

Papio hamadryas

Parahyaena brunnea

Pedetes capensis 
Pelea capreolus

Phacochoerus africanus

Potamochoerus larvatus

Praomys sp.

Procavia capensis

Pronolagus rupestris

Proteles cristatus

Raphicerus campestris

Raphicerus melanotis

Rattus rattus

Redunca arundinum

Redunca fulvorufula

Rhabdomys pumilio

Rhynchogale melleri

Saccostomus campestris

Soricidae

Suricata suricatta

Sylvicapra grimmia

Syncerus caffer 
Tatera leucogaster

Taurotragus oryx

Tragelaphus angasii

Tragelaphus scriptus

Tragelaphus strepsiceros

Vulpes chama

\section{Tick species}

Mammal host species

$\begin{array}{lllllllllllllllllllllllllllllll}32 & 33 & 34 & 35 & 36 & 37 & 38 & 39 & 40 & 41 & 42 & 43 & 44 & 45 & 46 & 47 & 48 & 49 & 50 & 51 & 52 & 53 & 54 & 55 & 56 & 57 & 58 & 59 & 60 & 61\end{array}$

Acinonyx jubatus

$+\quad-\quad+$

Aepyceros melampus

Aethomys chrysophilus

Aethomys namaquensis

Alcelaphus buselaphus

Antidorcas marsupialis

Atelerix frontalis

Bos indicus

Bos sp. 
Bos taurus

Canis lupus familiaris

Canis mesomelas

Capra hircus

Caracal caracal

Cephalophus natalensis

Ceratotherium simum

Chlorocebus aethiops

Civettictis civetta

Connochaetes gnou

Connochaetes taurinus

Crocuta crocuta

Cynictis penicillata

Damaliscus lunatus

Damaliscus pygargus

Diceros bicornis

Elephantulus

brachyrhynchus 
Elephantulus edwardii

Elephantulus myurus

Equus asinus

Equus burchelli

Equus caballus

Equus zebra

Felis catus

Felis nigripes

Felis silvestris

Galerella pulverulenta

Galerella sanguinea

Genetta genetta

Genetta sp.

Genetta tigrina

Giraffa camelopardalis

Hippotragus equinus

Hippotragus niger

Hystrix africaeaustralis 
Ichneumia albicauda

Ictonyx striatus

Lemniscomys rosalia

Leptailurus serval

Lepus capensis

Lepus saxatilis

Loxodonta africana

Lycaon pictus

Macroscelides

proboscideus

Mastomys coucha

Mastomys natalensis

Mellivora capensis

Mungos mungo

Neotragus moschatus

Oreotragus oreotragus

Oryx gazella

Otocyon megalotis 
Otolemur crassicaudatus

Otomys occidentalis

Otomys sp.

Ovis aries

Panthera leo

Panthera pardus

Papio hamadryas

Parahyaena brunnea

Pedetes capensis

Pelea capreolus

Phacochoerus africanus

Potamochoerus larvatus

Praomys sp.

Procavia capensis

Pronolagus rupestris

Proteles cristatus

Raphicerus campestris

Raphicerus melanotis 
Rattus rattus

Redunca arundinum

Redunca fulvorufula

Rhabdomys pumilio

Rhynchogale melleri

Saccostomus campestris

Soricidae

Suricata suricatta

Sylvicapra grimmia

Syncerus caffer

Tatera leucogaster

Taurotragus oryx

Tragelaphus angasii

Tragelaphus scriptus

Tragelaphus strepsiceros

Vulpes chama 
*Key to the tick species

1 Amblyomma hebraeum Koch, 1844

2 Amblyomma marmoreum Koch, 1844

3 Amblyomma nuttalli Dönitz, 1909

4 Amblyomma tholloni Neumann, 1899

5 Cosmiomma hippopotamensis_Denny, 1843

6 Dermacentor rhinocerinus_Denny, 1843

7 Haemaphysalis aciculifer Warburton, 1913

8 Haemaphysalis colesbergensis Apanaskevich and Horak, 2008

9 Haemaphysalis cooleyi Bedford, 1929

10 Haemaphysalis elliptica_Koch, 1844

11 Haemaphysalis hoodi Warburton and Nuttall, 1909

12 Haemaphysalis hyracophila Hoogstraal, Walker and Neitz, 1971

13 Haemaphysalis parmata Neumann, 1905

14 Haemaphysalis silacea Robinson, 1912

15 Haemaphysalis spinulosa Neumann, 1906

16 Haemaphysalis zumpti Hoogstraal and El Kammah, 1974

17 Hyalomma glabrum Delpy, 1949

18 Hyalomma rufipes Koch, 1844

19 Hyalomma truncatum Koch, 1844

20 Ixodes alluaudi Neumann, 1913

21 Ixodes aulacodi Arthur, 1956

22 Ixodes bakeri Arthur and Clifford, 1961

23 Ixodes cavipalpus Nuttall and Warburton, 1908

24 Ixodes corwini Keirans, Clifford and Walker, 1982 
26 Ixodes neitzi Clifford, Walker and Keirans, 1977

$27 \quad$ Ixodes pilosus Koch, 1844

28 Ixodes rhabdomysae Arthur, 1959

29 Ixodes rubicundus Neumann, 1904

$30 \quad$ Margaropus winthemi Karsch, 1879

31 Rhipicentor nuttalli Cooper and Robinson, 1908

32 Rhipicephalus appendiculatus Neumann, 1901

33 Rhipicephalus arnoldi Theiler and Zumpt, 1949

$34 \quad$ Rhipicephalus capensis Koch, 1844

35 Rhipicephalus decoloratus Koch, 1844 _Boophilus

36 Rhipicephalus distinctus Bedford, 1932

37 Rhipicephalus evertsi evertsi Neumann, 1897

38 Rhipicephalus evertsi mimeticus Dönitz, 1910

39 Rhipicephalus exophthalmos Keirans and Walker, 1993

40 Rhipicephalus follis Dönitz, 1910

41 Rhipicephalus gertrudae Feldman-Muhsam, 1960

42 Rhipicephalus glabroscutatum Du Toit, 1941

43 Rhipicephalus kochi Dönitz, 1905

$44 \quad$ Rhipicephalus lounsburyi Walker, 1990

45 Rhipicephalus lunulatus Neumann, 1907

46 Rhipicephalus maculatus Neumann, 1901

47 Rhipicephalus microplus_Canestrini, 1888 _Boophilus

$48 \quad$ Rhipicephalus muehlensi Zumpt, 1943

49 Rhipicephalus neumanni Walker, 1990 
$50 \quad$ Rhipicephalus nitens Neumann, 1904

51 Rhipicephalus oculatus Neumann, 1901

52 Rhipicephalus sanguineus_Latreille, 1806

53 Rhipicephalus simpsoni Nuttall, 1910

$54 \quad$ Rhipicephalus simus Koch, 1844

55 Rhipicephalus sulcatus Neumann, 1908

56 Rhipicephalus theileri Bedford and Hewitt, 1925

57 Rhipicephalus tricuspis Dönitz, 1906

$58 \quad$ Rhipicephalus turanicus Pomerantzev, 1940

59 Rhipicephalus warburtoni Walker and Horak, 2000

60 Rhipicephalus zambeziensis Walker, Norval and Corwin, 1981

61 Rhipicephalus zumpti Santos Dias, 1950 
Supplementary Material C. Phylogenetic tree of the 95 mammal host species extracted from Bininda-Emonds et al. (2007). The branch lengths are expressed in millions of years.

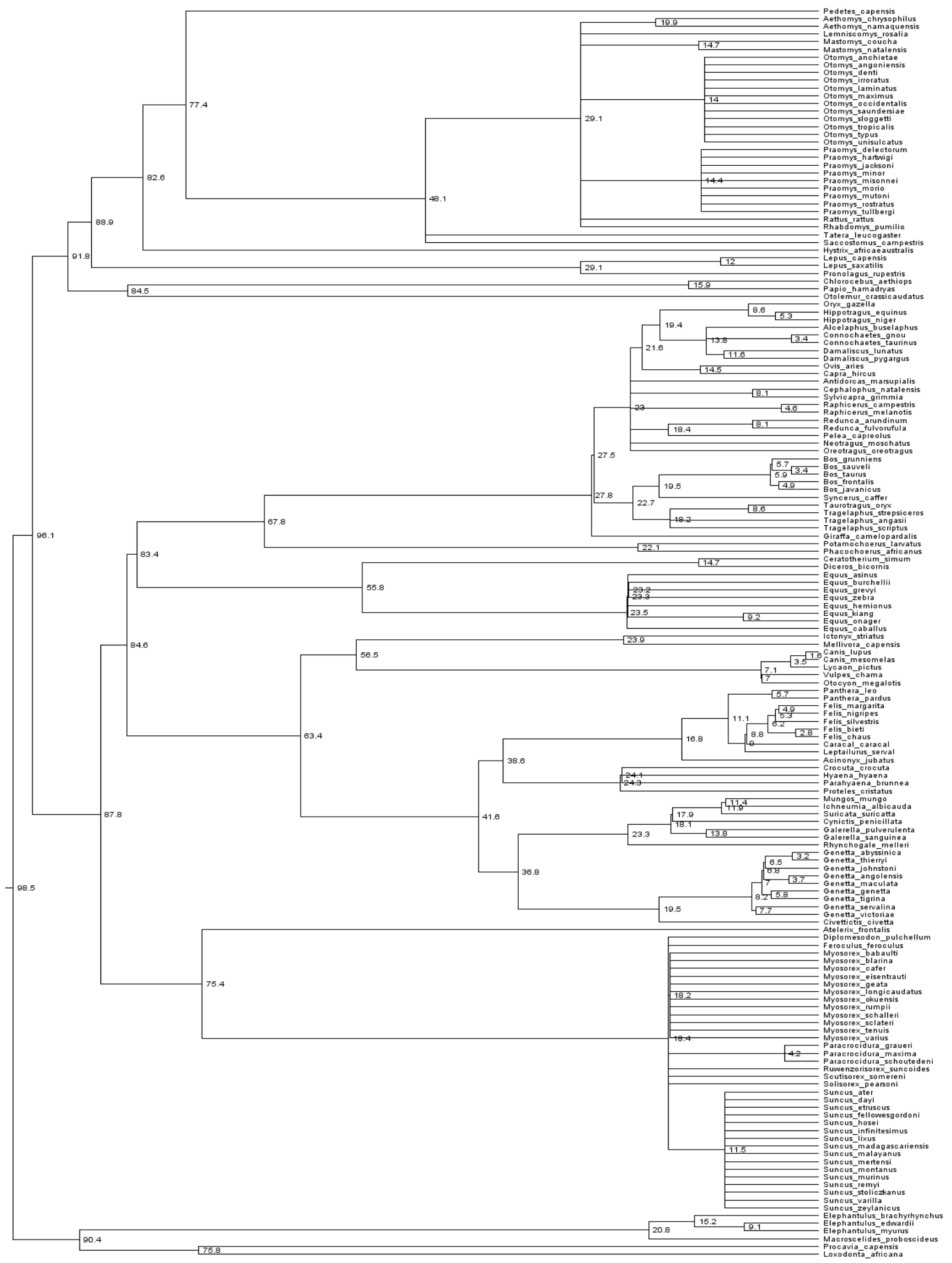


Supplementary Material D. The 61 tick species considered in this study, their scientific names, and indices ( $S_{\mathrm{TD}}$ and $S_{\mathrm{TD}} *$ ) values for ticks whatever their life stage (all), juveniles $(j u v)$ and adults $(a d)$. A higher $S_{\mathrm{TD}}$ or $S_{\mathrm{TD}} *$ index indicates a more generalist parasite. $N A$ means 'Not applicable' for tick species that fed on $<2$ mammal host species.

\begin{tabular}{|c|c|c|c|c|c|c|}
\hline Tick species scientific name & $\begin{array}{c}S_{\mathrm{TD}} \\
\text { all }\end{array}$ & $\begin{array}{l}S_{\mathrm{TD}} \\
\text { juv }\end{array}$ & $\begin{array}{c}S_{\mathrm{TD}} \\
\mathbf{a d}\end{array}$ & $\begin{array}{c}S_{\mathrm{TD}}{ }^{*} \\
\text { all }\end{array}$ & $\begin{array}{c}S_{\mathrm{TD}} * \\
\text { juv }\end{array}$ & $\begin{array}{c}S_{\mathrm{TD}} * \\
\mathbf{a d}\end{array}$ \\
\hline Amblyomma hebraeum Koch, 1844 & 70.99 & 70.99 & 63.96 & 63.63 & 64.98 & 49.84 \\
\hline Amblyomma marmoreum Koch, 1844 & 72.14 & 72.14 & NA & 61.81 & 61.81 & NA \\
\hline Amblyomma nuttalli Dönitz, 1909 & 16.8 & 16.8 & NA & 16.8 & 16.8 & NA \\
\hline Amblyomma tholloni Neumann, 1899 & 97.7 & 96.1 & NA & 97.99 & 96.1 & NA \\
\hline Cosmiomma hippopotamensis Denny, 1843 & NA & NA & NA & NA & NA & NA \\
\hline Dermacentor rhinocerinus (Denny, 1843) & 71.66 & 41.77 & 14.7 & 47.30 & 43.75 & 14.7 \\
\hline Haemaphysalis aciculifer Warburton, 1913 & 65.11 & 71.73 & 58.99 & 62.24 & 47.07 & 69.69 \\
\hline Haemaphysalis colesbergensis Apanaskevich and Horak, 2008 & 87.8 & NA & 87.8 & 87.80 & NA & 87.8 \\
\hline Haemaphysalis cooleyi Bedford, 1929 & NA & NA & NA & NA & NA & NA \\
\hline Haemaphysalis elliptica (Koch, 1844) & 76.42 & 78.42 & 65.97 & 60.07 & 80.53 & 30.59 \\
\hline Haemaphysalis hoodi Warburton and Nuttall, 1909 & NA & NA & NA & NA & NA & NA \\
\hline Haemaphysalis hyracophila Hoogstraal, Walker and Neitz, 1971 & 95.8 & 95.8 & NA & 97.45 & 94.85 & NA \\
\hline Haemaphysalis parmata Neumann, 1905 & 46.9 & 46.9 & 26 & 31.85 & 34.93 & 27.00 \\
\hline Haemaphysalis silacea Robinson, 1912 & 61.83 & 61.83 & 45.09 & 24.05 & 23.88 & 16.68 \\
\hline Haemaphysalis spinulosa Neumann, 1906 & 53.46 & 50.35 & 53.46 & 47.37 & 43.99 & 46.93 \\
\hline Haemaphysalis zumpti Hoogstraal and El Kammah, 1974 & 51.49 & 33.43 & 51.49 & 38.65 & 27.25 & 39.35 \\
\hline Hyalomma glabrum Delpy, 1949 & 81.42 & 83.73 & 56.05 & 80.39 & 35.49 & 66.41 \\
\hline Hyalomma rufipes Koch, 1844 & 63.68 & 60.95 & 44.97 & 72.76 & 22.21 & 51.26 \\
\hline Hyalomma truncatum Koch, 1844 & 72.04 & 88.08 & 62.83 & 75.46 & 34.17 & 60.39 \\
\hline Ixodes alluaudi Neumann, 1913 & 96.1 & NA & NA & 96.1 & NA & NA \\
\hline Ixodes aulacodi Arthur, 1956 & NA & NA & NA & NA & NA & NA \\
\hline
\end{tabular}


Ixodes bakeri Arthur and Clifford, 1961

Ixodes cavipalpus Nuttall and Warburton, 1908

Ixodes corwini Keirans, Clifford and Walker, 1982

Ixodes drakensbergensis Clifford, Theiler and Baker, 1975

Ixodes neitzi Clifford, Walker and Keirans, 1977

Ixodes pilosus Koch, 1844

Ixodes rhabdomysae Arthur, 1959

Ixodes rubicundus Neumann, 1904

Margaropus winthemi Karsch, 1879

Rhipicentor nuttalli Cooper and Robinson, 1908

Rhipicephalus appendiculatus Neumann, 1901

Rhipicephalus arnoldi Theiler and Zumpt, 1950

Rhipicephalus capensis Koch, 1844

Rhipicephalus decoloratus Koch, 1844 Boophilus

Rhipicephalus distinctus Bedford, 1932

Rhipicephalus evertsi evertsi Neumann, 1897

Rhipicephalus evertsi mimeticus Dönitz, 1910

Rhipicephalus exophthalmos Keirans and Walker, 1993

Rhipicephalus follis Dönitz, 1910

Rhipicephalus gertrudae Feldman-Muhsam, 1960

Rhipicephalus glabroscutatus Du Toit, 1941

Rhipicephalus kochi Dönitz, 1905

Rhipicephalus lounsburyi Walker, 1990

Rhipicephalus lunulatus Neumann, 1907

Rhipicephalus maculatus Neumann, 1901

Rhipicephalus microplus (Canestrini, 1888) Boophilus

Rhipicephalus muehlensi Zumpt, 1943

Rhipicephalus neumanni Walker, 1990 $\begin{array}{llllll}86.13 & 73.77 & 98.5 & 90.08 & 86.53 & 98.74\end{array}$

$\begin{array}{llllll}84.6 & \text { NA } & 84.6 & 84.6 & \text { NA } & 84.6\end{array}$

$\begin{array}{llllll}63.4 & \mathrm{NA} & 63.4 & 63.22 & \mathrm{NA} & 63.22\end{array}$

NA NA NA NA NA NA

NA NA NA NA NA NA

$\begin{array}{llllll}65.25 & 64.42 & 61.44 & 73.41 & 54.32 & 51.56\end{array}$

$\begin{array}{llllll}84.6 & \text { NA } & 84.6 & 84.6 & \text { NA } & 84.6\end{array}$

$\begin{array}{llllll}80.12 & 85.59 & 76.01 & 84.02 & 76.83 & 67.89\end{array}$

$\begin{array}{llllll}79.81 & 79.81 & 54.1 & 75.77 & 76.81 & 73.32\end{array}$

$\begin{array}{llllll}67.25 & \mathrm{NA} & 67.25 & 85.97 & \mathrm{NA} & 70.22\end{array}$

$\begin{array}{llllll}67.65 & 66.78 & 63.33 & 49.32 & 42.23 & 64.89\end{array}$

$\begin{array}{llllll}88.71 & 87 & 86.13 & 93.62 & 93.66 & 79.28\end{array}$

$\begin{array}{llllll}72.33 & 83.55 & 55.73 & 72.09 & 60.10 & 64.45\end{array}$

$\begin{array}{llllll}66.64 & 67.87 & 54.3 & 55.81 & 51.99 & 62.62\end{array}$

$\begin{array}{llllll}90.42 & 89.48 & 96.03 & 97.15 & 97.06 & 95.83\end{array}$

$\begin{array}{llllll}64.49 & 64.33 & 51.90 & 60.91 & 58.76 & 60.26\end{array}$

$96.1 \quad$ NA $\quad$ NA $\quad 96.1 \quad$ NA $\quad$ NA

$\begin{array}{llllll}58.99 & 72.6 & 40.3 & 71.96 & 28.23 & 35.21\end{array}$

$\begin{array}{llllll}80.39 & 81.97 & 69.64 & 73.02 & 90.23 & 64.55\end{array}$

$\begin{array}{llllll}78.06 & 71.41 & 63.52 & 86.67 & 53.19 & 79.18\end{array}$

$\begin{array}{llllll}61.84 & 61.84 & 55.87 & 28.83 & 28.10 & 34.19\end{array}$

$\begin{array}{llllll}55.15 & 59.25 & 55.15 & 41.29 & 51.70 & 30.98\end{array}$

$\begin{array}{llllll}49.11 & \text { NA } & 37.37 & 27.53 & \text { NA } & 24.50\end{array}$

$\begin{array}{llllll}84.6 & \text { NA } & 84.6 & 84.6 & \text { NA } & 84.6\end{array}$

$\begin{array}{llllll}68.25 & 63.17 & 74.69 & 62.16 & 43.02 & 78.68\end{array}$

$\begin{array}{llllll}46.82 & 27.5 & 46.82 & 29.93 & 27.57 & 29.96\end{array}$

$\begin{array}{llllll}56.41 & 56.41 & 37.47 & 26.67 & 27.43 & 19.84\end{array}$

$\begin{array}{llllll}22.26 & \text { NA } & 22.26 & 22.25 & \text { NA } & 22.25\end{array}$ 
Rhipicephalus nitens Neumann, 1904

Rhipicephalus oculatus Neumann, 1901

Rhipicephalus sanguineus (Latreille, 1806)

Rhipicephalus simpsoni Nuttall, 1910

Rhipicephalus simus Koch, 1844

Rhipicephalus sulcatus Neumann, 1908

Rhipicephalus theileri Bedford and Hewitt, 1925

Rhipicephalus tricuspis Dönitz, 1906

Rhipicephalus turanicus Pomerantzev, 1940

Rhipicephalus warburtoni Walker and Horak, 2000

Rhipicephalus zambeziensis Walker, Norval and Corwin, 1981

Rhipicephalus zumpti Santos Dias, 1950 $\begin{array}{llllll}63.7 & 63.7 & 63.7 & 33.99 & 33.68 & 43.29\end{array}$

$\begin{array}{llllll}74.18 & 79.68 & 66.98 & 43.75 & 36.37 & 44.64\end{array}$

NA NA NA NA NA NA

$\begin{array}{llllll}77.53 & \text { NA } & 84.6 & 77.53 & \text { NA } & 84.6\end{array}$

$\begin{array}{llllll}77.86 & 73.90 & 70.09 & 62.41 & 75.27 & 52.28\end{array}$

$\begin{array}{llllll}63.4 & \mathrm{NA} & 63.4 & 63.4 & \mathrm{NA} & 63.4\end{array}$

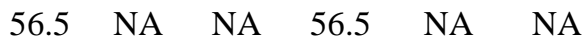

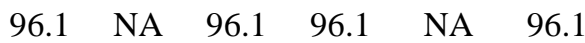

$\begin{array}{llllll}66.67 & 79.68 & 61.04 & 69.27 & 65.99 & 65.07\end{array}$

$\begin{array}{llllll}81.46 & 86.90 & 72.79 & 88.01 & 85.67 & 76.11\end{array}$

$\begin{array}{llllll}72.30 & 70.43 & 75.72 & 80.29 & 81.99 & 66.53\end{array}$

$\begin{array}{llllll}84.6 & \text { NA } & 84.6 & 84.6 & \text { NA } \quad 84.60\end{array}$ 